\title{
Endoscopic Mucosal Resection with Circumferential Incision in Difficult Colorectal Lesions
}

\author{
Marta Gravito-Soares ${ }^{\mathrm{a}, \mathrm{c}}$ Elisa Gravito-Soares ${ }^{\mathrm{a}, \mathrm{c}}$ Pedro Amaro $^{\mathrm{a}}$ João Fraga ${ }^{\mathrm{b}}$ \\ Luís Toméa, c \\ ${ }^{a}$ Gastroenterology Department, Centro Hospitalar e Universitário de Coimbra, Coimbra, Portugal; \\ bPathology Department, Centro Hospitalar e Universitário de Coimbra, Coimbra, Portugal; \\ 'Faculty of Medicine, University of Coimbra, Coimbra, Portugal
}

Keywords

Endoscopic mucosal resection with circumferential incision .

Colorectal lesions · Fibrosis

\section{Resseção Mucosa Endoscópica com Incisão Circunferencial em Lesões Colo-Retais Difíceis}

\section{Palavras Chave}

Resseção mucosa endoscópica com incisão circunferencial · Lesões colo-retais · Fibrose

A 76-year-old man with a medical history of hypertension and atrial fibrillation under apixaban was submitted to anterior resection for rectal adenocarcinoma following neoadjuvant radiochemotherapy. At the fifth year of postoperative endoscopic surveillance, an 18$\mathrm{mm}$ flat lesion (Paris type 0-IIb, nongranular laterally spreading lesion [LST-NG] and Kudo pit pattern type IIIs/IV) was found at the proximal transverse colon. A conventional endoscopic mucosal resection (EMR) attempt was ineffective due to nonlifting of the central

\section{KARGER}

E-Mail karger@karger.com www.karger.com/pjg
(C) 2018 Sociedade Portuguesa de Gastrenterologia Published by S. Karger AG, Basel

Karger

Open access

This article is licensed under the Creative Commons AttributionNonCommercial-NoDerivatives 4.0 International License (CC BYNC-ND) (http://www.karger.com/Services/OpenAccessLicense). Usage and distribution for commercial purposes as well as any distribution of modified material requires written permission. portion of the lesion; biopsies were taken and the site was tattooed (SPOT ${ }^{\circledR}$ GI Supply, Camp Hill, PA, USA). Pathology showed a low-grade dysplasia adenoma and the patient was referred to our institution. Colonoscopy showed the $18-\mathrm{mm}$ flat lesion in an area of tattooed mucosa (Fig. 1a). Initially, inject-and-cut EMR and a modified aspirative EMR using a rim-free cap were tried without success. Therefore, it was decided to perform a hybrid endoscopic submucosal dissection (ESD). First, an injection of submucosa using epinephrine-saline mixture $(1: 100,000)$ and methylene blue was performed with difficulty in elevating the central portion of the lesion; then, submucosal access and circumferential incision were made using a ClearCut-knife $2 \mathrm{~mm}$ I-type (Finemedix Co. Ltd, Daegu, Republic of Korea); and, finally, an en-bloc resection using an oval $15-\mathrm{mm}$ diathermic snare (Olympus, Spain) was performed without complications (Fig. 1b-d). Pathology of resection specimen (Fig. 2) showed a tubular adenoma with low-grade dysplasia (R0 resection) (Fig. 3a, b). Periprocedural management included stopping anticoagulation in the

M.G.-S. and E.G.-S. contributed equally to this work.

Dr. Marta Gravito-Soares

Gastroenterology Department, Centro Hospitalar e Universitário de Coimbra Praceta Prof. Mota Pinto

PT-3000-075 Coimbra (Portugal)

E-Mail ms18498@gmail.com 
Fig. 1. Endoscopic mucosal resection with circumferential incision of a flat lesion at the proximal transverse colon. a Endoscopic finding of an 18-mm flat lesion Paris type 0-IIb, LST-NG and Kudo pit pattern type IIIs/IV under white light imaging, located in a tattooed area. b After submucosal injection of epinephrine-saline mixture $(1: 100,000)$ and methylene blue, a circumferential incision was performed using ClearCut-knife $2 \mathrm{~mm}$ I-type. c Snaring technique to achieve complete resection. d En-bloc resection without complications and eschar inspection.

Fig. 2. Resected specimen.

Fig. 3. Pathology of resected specimen revealing a tubular adenoma with low-grade dysplasia with free vertical margin. a $\mathrm{H} \& \mathrm{E}$, $\times 20$. b H\&E, $\times 100$.
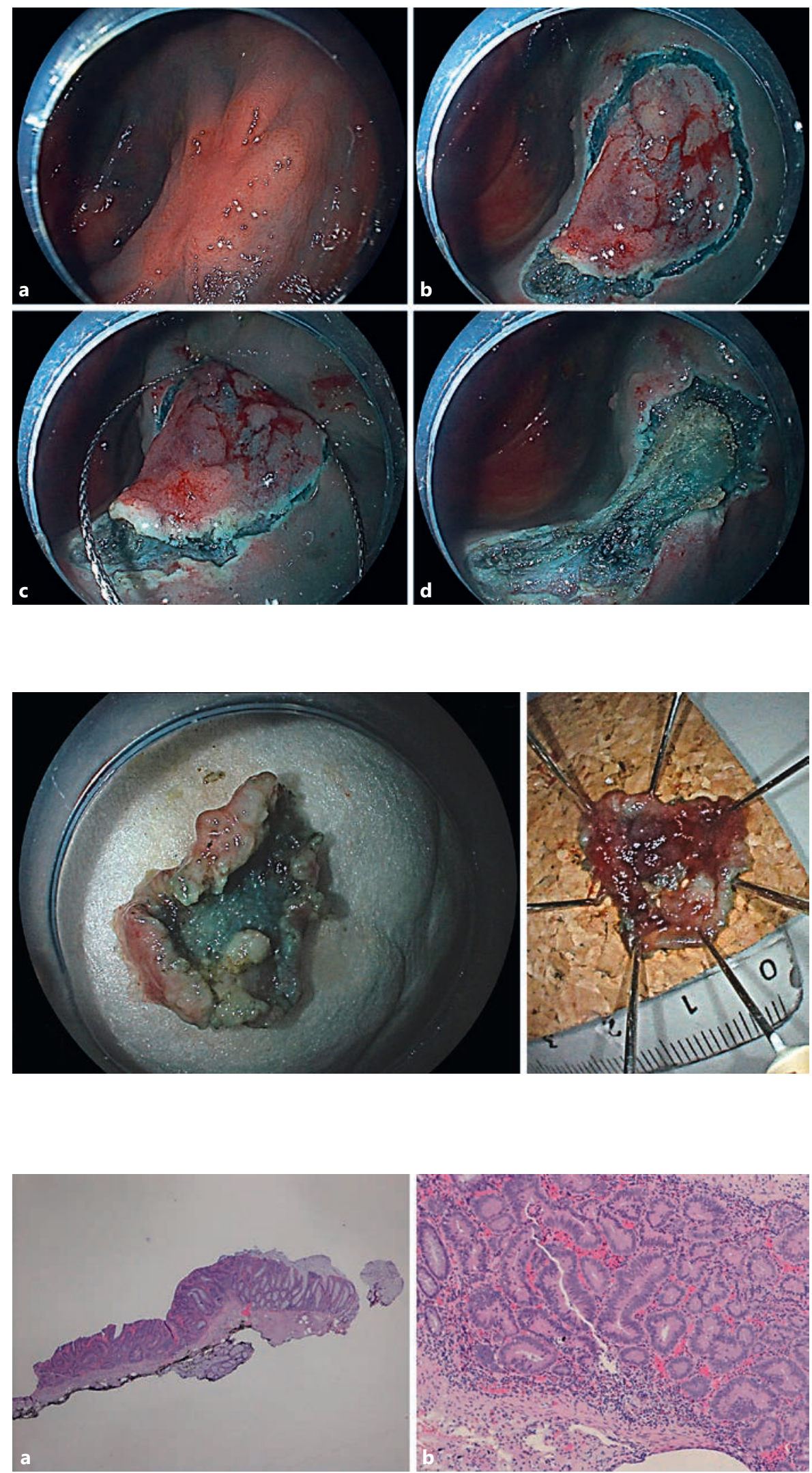

Gravito-Soares/Gravito-Soares/Amaro/ Fraga/Tomé 
previous $48 \mathrm{~h}$ and resumption 1 week later, after postprocedure low-molecular-weight heparin bridging. A 6-month follow-up colonoscopy with biopsies showed no recurrence.

EMR has been widely used in colorectal polyps $[1,2]$ being usually piecemeal for lesions $>20 \mathrm{~mm}$. Contrariwise, ESD has a higher en-bloc resection, complete resection, and lower local recurrence rates $[2,3]$. However, several drawbacks, including a technically demanding and time-consuming procedure, long learning curve, and significant risk of complications, limit its colorectal use $[1,3,4]$. Currently, ESD has been proposed for hard-toresect lesions, such as LST-NG or nonlifting lesions, that otherwise require surgical resection $[1,2,4,5]$.

Techniques combining ESD and EMR have been developed to minimize ESD limitations, including EMR with circumferential incision (EMR-CI) and ESD-hybrid (ESD-H) [1, 3-5]. EMR-CI consists in an EMR following circumferential mucosal incision without partial submucosal dissection, avoiding snare slippage $[1,3,5]$. For large colorectal lesions ( $>20 \mathrm{~mm}$ ), ESD revealed superior to EMR-CI or ESD-H due to the higher complete resection rate $[2,4,5]$. However, limited published studies comparing these techniques for lesions $<20 \mathrm{~mm}$ showed no differences in terms of complete resection or safety [3, 5]. Therefore, EMR-CI can be considered an alternative to ESD without its drawbacks and much less cost than other endoscopic options such as full-thickness resection $[4,5]$.

In this case, the lesion morphology, tattooing, fibrosis due to previous resection attempt, and biopsies could have contributed to resection technical difficulties. Despite the recommendation to take biopsies and tattooing before referring to an expert center [2], this case highlights the importance of a good tattooing technique (at least $2-3 \mathrm{~cm}$ distal to the lesion) in order not to limit subsequent resection. EMR-CI revealed to be a successful and safe alternative technique for ESD in hard-to-resect colorectal lesions up to $20 \mathrm{~mm}$.

\section{Statement of Ethics}

Protection of Human and Animal Subjects: The authors declare that no experiments were performed on humans or animals for this study. Confidentiality of Data: The authors declare that they have followed the protocols of their work center on the publication of patient data. Right to Privacy: The authors declare that no patient data appear in this article. Informed Patient Consent for Publication: Informed consent was obtained for this case report.

\section{Disclosure Statement}

The authors declare no disclosures to report.

\section{Author Contributions}

Marta Gravito-Soares and Elisa Gravito-Soares contributed equally, writing the manuscript and reviewing the literature. Marta Gravito-Soares is the article guarantor. Pedro Amaro and Luis Tomé contributed to critical revision of the manuscript for important intellectual content.
References
1 Okamoto K, Muguruma N, Kagemoto K, et al: Efficacy of hybrid endoscopic submucosal dissection (ESD) as a rescue treatment in difficult colorectal ESD cases. Dig Endosc 2017; 29(suppl 2):45-52.

2 Ferlitsch M, Moss A, Hassan C, et al: Colorectal polypectomy and endoscopic mucosal resection (EMR): European Society of Gastrointestinal Endoscopy (ESGE) Clinical Guideline. Endoscopy 2017;49:270-297.
-3 De Ceglie A, Hassan C, Mangiavillano B, et al: Endoscopic mucosal resection and endoscopic submucosal dissection for colorectal lesions: a systematic review. Crit Rev Oncol Hematol 2016;104:138-155.

-4 Kim YJ, Kim ES, Cho KB, et al: Comparison of clinical outcomes among different endoscopic resection methods for treating colorectal neoplasia. Dig Dis Sci 2013;58:1727-1736.

5 Gaglia A, Sarkar S: Evaluation and long-term outcomes of the different modalities used in colonic endoscopic mucosal resection. Ann Gastroenterol 2017;30:145-151. 